\title{
Optimal alternative therapy for metastatic HER2- positive breast cancer progression who previously received trastuzumab-based therapy: a systematic review and network meta-analysis
}

Fubin Feng

Qingdao University Medical College

Tingting Zhang

Shandong University of Traditional Medicine

Fang Yin

Weifang People's Hospital

Cun Liu

Shandong University of Traditional Chinese Medicine

Jing Zhuang

Weifang Traditional Chinese Hospital

\section{Xue Wang}

Qingdao University Medical College

Lingyu Qi

Shandong University of Traditional Chinese Medicine

Jinhui Tian

Lanzhou University

Changgang Sun ( $\square$ scgdoctor@126.com )

Qingdao University Medical College https://orcid.org/0000-0002-6648-3602

Research article

Keywords: breast cancer, HER2-positive, HER2-targeted agents, disease progression, trastuzumab, network meta-analysis

Posted Date: November 19th, 2019

DOI: https://doi.org/10.21203/rs.2.17491/v1

License: (9) (1) This work is licensed under a Creative Commons Attribution 4.0 International License. Read Full License 


\section{Abstract}

Background: Trastuzumab remains the standard protocol recommended for human epidermal growth factor receptor 2 (HER2)-positive metastatic breast cancer (MBC). After disease progression, the decision to continue trastuzumab treatment in combination with another type of chemotherapy, or to replace it with another HER2-targeted therapy, has not been conclusive.

Methods: We systematically searched databases and extracted data from randomized controlled trials (RCTs) on patients who experienced disease progression after receiving trastuzumab-based therapies. Paired meta-analyses were performed to provide a comparison between patients continuously received trastuzumab-based therapy and those receiving other targeted therapies. Bayesian network meta-analysis was used to synthesize available evidence of direct or indirect comparison.

Results: The 10 selected articles that included 3,158 patients were analyzed. The paired meta-analysis showed a $29 \%$ (hazard ratio (HR): $0.71 ; 95 \%$ confidence interval $(\mathrm{Cl}): 0.60-0.85$ ) reduction in mortality risk for patients continued receiving trastuzumab-based therapy than those receiving other targeted regimen. Bayesian network meta-analysis suggested that pertuzumab and trastuzumab plus capecitabine (PHC) showed an improvement in the overall survival (OS), with the highest surface under the cumulative ranking (SUCRA) $(0.962(82.3 \%))$. In terms of progression-free survival (PFS) and objective response rate (ORR), trastuzumab emtansine (T-DM1) showed the highest SUCRA $(0.949(73.2 \%)$ and 0.997 (98.5\%), respectively).

Conclusions $₫$ Continuing trastuzumab with another type of chemotherapy is a better option for patients who experience disease progression after receiving trastuzumab-based therapy. Patients treated with PHC had the highest OS. Meanwhile, patients treated with T-DM1 showed better PFS and ORR than those treated with other regimens.

\section{Background}

Human epidermal growth factor receptor-2 (HER2) amplification occurs in $15 \%-20 \%$ of patients with breast cancer and is associated with more aggressive biological processes and poor prognosis $[1,2]$. Since trastuzumab has been proven beneficial for both early-stage and metastatic HER2-positive breast cancer, trastuzumab plus paclitaxel or docetaxel has been used as the standard first-line treatment for those group of patients [3-5].

Trastuzumab combined with adjuvant chemotherapy significantly improved the prognosis of patients with HER-2 positive breast cancer [6]. The HERNATA study found that trastuzumab plus vinorelbine is equally effective as trastuzumab plus docetaxel in the treatment of metastatic breast cancer [7]. The NEfERTT trial indicated that the progression-free survival (PFS) of patients treated with trastuzumab plus paclitaxel was similar to that of patients treated with neratinib plus paclitaxel [8]. Indeed, a dual HER2 blockade of trastuzumab and pertuzumab provides median PFS benefits over trastuzumab plus 
docetaxel for HER2-positive metastatic breast cancer [9]. In the last decades, numerous HER2-directed therapies has changed the course of HER2-positive breast cancer.

Nevertheless, most patients experience progression within 1 year, because of intrinsic or acquired resistance to trastuzumab-based therapy. The reasons for this resistance have not yet been well explicated. Some trials have reported the effectiveness of recombinant anti-HER2 agents as treatment for patients with metastatic breast cancer who experienced progression after receiving trastuzumab-based therapy. In the German Breast Group 26 trial, continuous use of trastuzumab plus capecitabine was more effective than treatment with capecitabine alone in patients with progression who were heavily pretreated with trastuzumab [10]. The PHEREXA study indicated that the addition of pertuzumab to trastuzumab and capecitabine did not improve PFS [11]. After switching to other HER2-directed therapies, the results were inconsistency in the trails of EMILIA [12] and LUX-Breast 1 [13].

Therefore, the decision to continue trastuzumab treatment even after disease progression is a pivotal perplexity for clinicians. The use of trastuzumab in combination with a different chemotherapy, or the use of other HER2-targeted therapies, remains inconclusive. We therefore aimed to conduct systematic review and meta-analysis to determine the optimal therapy for HER2-positive metastatic breast cancer patients who experienced disease progression after receiving trastuzumab-based therapies. We also aimed to address the above issues in some terms and provide a reference for clinicians.

\section{Methods}

\section{Literature and search strategy}

PubMed, Embase, and Cochrane Library for randomized controlled trials (RCTs) of metastatic HER2positive breast cancer targeted therapy were searched up to July 31, 2018. To avoid missing documents, we searched the abstracts of the European Society for Medical Oncology (ESMO) and American Society of Clinical Oncology (ASCO). We also manually searched the reference lists of the included bibliographies and related reviews to supplement the primary sources. The gray literatures were excluded. The Medical Subject Headings/Emtree terms combined with free-text words, "breast cancer," "breast neoplasms," "randomized controlled trial," and known HER2-targeted agents (e.g., "T-DM1," "pertuzumab," "trastuzumab," and "lapatinib"), were the keywords used during the search. To avoid the omission of relevant literatures, we searched for articles that included a discussion on the pretreatment regimens and the inclusion and exclusion criteria for rigorous screening during follow-up. The search strategy was made by two authors, one with a background in carcinoma (Fubin Feng) and the other in advanced statistics (Jinhui Tian). The meta-analysis was reported according to the Preferred Reporting Items for Systematic Reviews and Meta-Analyses (PRISMA) guidelines [14].

\section{Selection criteria}

The following publications were included: (1) prospective phase II or III RCTs, (2) RCTs that were conducted among patients with pathologically confirmed HER-positive breast cancer, (3) RCTs that were 
conducted among patients with metastatic or advanced stage breast cancer, (4) RCTs that were conducted among patients with disease progression during or after trastuzumab-based therapy, (5) RCTs that were conducted among patients who were permitted but not required to receive anthracyclines and taxanes, (6) RCTs that contained at least two arms, and (7) RCTs with extractable outcomes (e.g., PFS, overall survival (OS), objective response rate (ORR)). By contrast, studies that included patients treated with two or more HER2-directed regimens in an advanced setting, studies that included patients who received endocrine therapy, and studies that were performed in patients treated with immunotherapeutic agents were excluded. The independent investigators (Fubin Feng and Tingting Zhang) evaluated the titles and abstracts of all included studies. If discrepancies existed, a third reviewer (Jinhui Tian) was consulted until a consensus was reached.

\section{Data extraction and quality assessments}

The authors (Fubin Feng and Tingting Zhang) extracted the relevant data from the original text according to the pre-designed form. The extracted data were as follows: first author's name, publication year, total number of patients in each RCT, treatment setting (dose, frequency, and treatment duration), funding source, characteristics of participants, and primary outcomes (e.g., PFS, OS, and ORR). We used the Cochrane Collaboration's risk of bias assessment tool to assess the risk of bias of included studies and recorded the evidence in order to provide a conclusion [15]. All studies were rated as follows across seven specified domains: "low risk of bias," "high risk of bias," or "unclear risk of bias." If discrepancies existed, the two authors need to reach a consensus via discussion.

\section{Statistical methods}

In the traditional paired meta-analysis, the regimens with trastuzumab and those without trastuzumab were compared. Hazard ratios (HR) and 95\% confidence intervals (Cls) in PFS and OS were extracted from the included studies. The natural logarithm of HR and standard error of PFS and OS were pooled for the traditional meta-analysis, and then the effect size of odds ratios (ORs) were also calculated. The heterogeneity of the pairwise comparisons was assessed using $\mathrm{I}^{2}$ and expressed as $\mathrm{p}$ values. If the values of $\mathrm{I}^{2} \geq 50 \%$ indicated a large amount of inconsistency, then a random-effect model was used in the analyses. When the values were below $50 \%$, a fixed-effect model was used in the analyses [16]. Using the STATA 13.0 command, a network plot was drawn to provide a direct comparison between the two interventions [17].

A network meta-analysis (NMA) with a Bayesian statistical model was used to indirectly compare two or more interventions. We used the WinBUGS version 1.4.3 (MRC Biostatistics Unit, Cambridge, UK) in the analysis, which employs Markov chain Monte Carlo methods. The selection of fixed model or random model was based on the deviance information criteria (DIC) value. The surface under the cumulative ranking (SUCRA) was used to rank the effectiveness of regimens in the network analysis [18]. As only a closed loop was presented in the meta-analysis, the node-splitting method was used to evaluate the inconsistencies between direct and indirect comparison [19]. A meta-package was used to identify the 
inconsistencies within a closed loop. A funnel plot was used to evaluate the presence of publication bias, and the Egger test was used to check for asymmetries in the funnel plot. The results of Begg's and Egger's test demonstrated no significant publication bias $(p>0.05)$ [20]. The statistical analyses were performed using STATA. The risk of bias was evaluated using the Review Manager (Version 5.3); creation of a network plot and analysis of SUCRA were performed using STATA Version 13.0 (Stata Corporation, College Station, TX, USA).

\section{Results}

\section{Overview of the literature search}

A total of 3,214 studies were identified by database search, of which 795 duplicate articles were excluded. Of the remaining studies ( $n=2,419), 2,375$ articles were excluded as they did not meet the inclusion criteria after screening the titles and abstracts. A total of 44 publications were selected for full review. The following trials were excluded: single-arm trails $(n=12)$, trials with conference abstract and no relevant data $(n=9)$, non-RCTs $(n=7)$, and trials comprised only of one study $(n=6)$. At length, 10 articles of 9 RCTs met the inclusion criteria. The PRISMA diagram is depicted in Figure 1.

Figure 1. PRISMA flow diagram of the study selection process

\section{Characteristics of the included studies}

The 10 selected articles (9 RCTs), which included 3,158 patients, were published from 2006 to 2018 . The median age of the patients was 51-59 yrs, and the number of patients ranged from 43 to 496 . Seven different treatment regimens were assessed based on the network plot for direct or indirect comparisons: the $\mathrm{LC}$ regimen, $\mathrm{HC}$ regimen, $\mathrm{PHC}$ regimen, lapatinib plus vinorelbine (LV) regimen, neratinib, T-DM1, and capecitabine [10-12,21-24]. The other four regimens that were not included in the network analysis but were included in the paired meta-analysis were as follows: trastuzumab plus vinorelbine (HV regimen), afatinib plus vinorelbine (AV regimen), lapatinib plus trastuzumab (HL regimen), and lapatinib regimen $[13,25,26]$. The direct and indirect relationships of those regimens are shown in Figure 2. Seven included trials demonstrated the direct and indirect comparisons between LC regimen and other regimens, which was finally performed in the Bayesian analysis. All trials, except the EGF104900, that have explicitly provided the data on PFS, OS, and ORR were reported in one study. The EGF104900 trial reported the data on PFS and OS in two publications [25,26]. All trials had two arms and presented the hormone receptor status; patients who received continuous trastuzumab-based therapy were reported in five studies $[10,11,13,21,25]$, of which one study compared the effects of trastuzumab mono anti-HER2 therapy with that of dual anti-HER2 regimens [11]. The characteristics of the included studies were depicted in Table 1, and the studies were considered reliable.

Figure 2. Network diagram of study comparisons for Bayesian network meta-analysis. (A) All included patients; (B) patients included in the network meta-analysis 
Notes: The size of each node is proportional to the number of patients who received the treatment. The widths of the lines are proportional to the number of studies comparing a treatment arm. LC, lapatinib plus capecitabine; $\mathrm{HC}$, trastuzumab plus capecitabine; $\mathrm{PHC}$, pertuzumab and trastuzumab plus capecitabine; LV, lapatinib plus vinorelbine; T-DM1, trastuzumab emtansine; HV, trastuzumab plus vinorelbine; $\mathrm{AV}$, afatinib plus vinorelbine; $\mathrm{HL}$, lapatinib plus trastuzumab

\section{Risk of bias assessment}

The variable qualities of nine included RCTs is shown in Figure 3. Five trials had an unclear risk for random sequence generation $[10,22,23,24,25]$. All trials were open label and two were thought exhibit attrition bias due to incomplete outcomes data $[13,24]$. Two articles reported the independent review facility-assessed PFS $[11,12]$. Meanwhile, one trial did not report the OS clinical data in the subgroup analysis and only mentioned the PFS at specified time points [21].

Figure 3. Cochrane risk of bias tool assessment (+: low risk of bias;:-: high risk of bias; and ?: unclear risk of bias)

\section{Results of direct comparisons}

Paired meta-analysis was performed to compare the effects of continuing trastuzumab-based therapy and switching to other targeted regimen, and four publications were included in the analysis $[10,13,21,26]$. Results showed a $29 \%$ reduction in the mortality risk (HR: $0.71 ; 95 \% \mathrm{Cl}: 0.60-0.85 ; \mathrm{I}^{2}$ : $0 \%$; heterogeneity: $p=0.915$; four trials; 1,046 patients). The PFS also reflects the benefit of continuing trastuzumab-based therapy over switching to other targeted regimen (HR: 0.79; $95 \% \mathrm{Cl}: 0.68-0.91 ; \mathrm{I}^{2}: 0 \%$ ); however, the ORR did not reflect the benefit of continuing trastuzumab-based therapy (HR: $1.16 ; 95 \%$ Cl: $0.98-1.37 ; I^{2}$ : $55.2 \%$; heterogeneity: $p=0.082$ ). A forest plot of the direct comparison results is depicted in Figure 4.

Figure 4. Forest plot of the direct comparison results

Notes: Fixed-effects meta-analyses of the results (A) PFSs, (B) OSs, and (C) ORRs among the treatment regimens and a direct comparison between continued trastuzumab-based therapy and switching to other targeted regimen. The size of the gray shaded area indicates the weight of each study. Horizontal lines show $95 \% \mathrm{Cls}$. HR<1 is in favor of the continued trastuzumab-based therapy.

Abbreviations: HR, hazard ratio; PFS, progression-free survival; OS, overall survival; OR, odds ratio; ORR, objective response rate

\section{Bayesian network meta-analysis}

As shown in Figure 2, there was a closed triangular loop (closed paths involving three different treatments) in lapatinib plus capecitabine-trastuzumab plus capecitabine-capecitabine. The inconsistency factors (IFs) was 0.55 (95\% Cl: $0.00-1.20$; heterogeneity: $p=0.092)$ for PFS and 0.36 ( $95 \%$ Cl: $0.00-1.40$; heterogeneity: $p=0.501)$, with no evidence of inconsistencies between direct and indirect 
evidence. The IF value was closer to 0 , which indicates a greater consistency between direct and indirect comparison. In the meta-analysis, we used LC as the reference regimen as the effects of most regimens were similar to that of lapatinib plus capecitabine by direct and indirect comparison according to the network plot. For the NMA of PFS, OS and ORR, we included seven trials and seven direct and indirect comparisons (10-12,21-24) were made. Other regimens were excluded in the meta-analysis, as direct comparisons were made. A comprehensive analysis of the efficacy of these regimens was performed in order to provide a comparison. Based on the DIC value, the fixed-effects model was chosen in the present NMA.

The results of the NMA showed that the PHC regimen would significantly improve OS compared with the LC regimen (HR: $0.49 ; 95 \% \mathrm{Cl}: 0.27-0.88$ ) and $\mathrm{HC}$ regimen (HR: $0.68 ; 95 \% \mathrm{Cl}: 0.51-0.90)$; T-DM1 showed better PFS compared with LC (HR: 0.65; 95\% Cl: 0.55-0.77) and HC (HR: 0.65; 95\% Cl: 0.46-0.93). Some of the results in a form of inverse are presented in Table 2. All the included regimens, except for neratinib, showed significant PFS compared with capecitabine (HR: 0.70; 95\% Cl: 0.46-1.06). T-DM1 showed better ORR compared with other regimens.

In terms of rank, pertuzumab and trastuzumab plus capecitabine showed the highest SUCRA (0.962(82.3\%)), with an improved OS, followed by T-DM1 (SUCRA: 0.756). For PFS and ORR, the T-DM1 regimen showed the highest SUCRA $(0.949(73.2 \%)$ and $0.997(98.5 \%))$ and was considered as the most effective treatment. Details are presented in Figures 5 and Table 3.

Figure 5. The surface under the cumulative ranking probability curve (SUCRA) of the comparisons

Note: The SUCRA of (A) PFSs, (B) OSs, and (C) ORRs. The larger the SUCRA, the higher the ranking

\section{Publication bias}

The funnel plots did not reveal any evidence of obvious asymmetry for PFS, OS, and ORR (Figure 6). In the Egger's test, the $p$ values for PFS, OS, and ORR were $0.741,0.721$, and 0.262 , respectively, and no significant publication bias was observed in the included studies.

Figure 6. Funnel plot for publication bias. (A) PFS, (B) OS, and (C): ORR

Abbreviations: PFS, progression-free survival; OS, overall survival; ORR, objective response rate

\section{Discussion}

Our present meta-analysis on the optimal alternative regimen for HER2-positive metastatic breast cancer patients who developed trastuzumab resistance, which was not reported in other relevant published studies, had some notable findings.

To determine whether continuous use of trastuzumab is beneficial for HER2-positive metastatic breast cancer (MBC) patients previously treated with trastuzumab, a traditional meta-analysis was conducted 
and suggested that patients who received continuous trastuzumab-based therapy showed better PFS and OS than those who received non trastuzumab-based therapy. The HR for OS and PFS reduced ( $29 \%$ and $21 \%$, respectively) and had lesser inconsistencies. However, for ORR, no significant difference was observed in our meta-analysis (HR: 1.16; $95 \% \mathrm{Cl}$ : 0.98-1.37). This suggests that trastuzumab combined with another type of chemotherapy remains a better option in this setting. However, the progress on prior trastuzumab-based therapy within 1 year sometimes suggested superior results of PFS in the group lapatinib plus capecitabine than trastuzumab plus capecitabine. Some previous studies predicted that those patients who developed intrinsic resistance or early resistance to trastuzumab might be not indicated for continuous trastuzumab therapy [21]. The definition of trastuzumab resistance is challenging; as indicated in some trials, a considerable proportion of patients retain sensitivity to trastuzumab after experiencing progression during prior trastuzumab-based therapy.

The network analysis suggested that the PHC regimen may result in a survival benefit compared with LC (HR; 0.49; 95\% Cl: 0.27-0.88) and HC (HR: 0.68; 95\% Cl: 0.51-0.90). Meanwhile, the PHC regimen showed the highest SUCRA (0.962(82.3\%)), which will more likely indicate improvement in OS, followed by T-DM1. These efficacy data, as well as those previously reported in the first-line treatment of HER2-positive breast cancer. The dual HER2 blockade with trastuzumab and pertuzumab in addition to docetaxel significantly prolonged PFS and OS compared with placebo plus trastuzumab plus docetaxel, when used as first-line therapy for HER2-positive metastatic breast cancer, as reported in the CLEOPATRA trial $[9,27]$. In a trial conducted among 88 patients treated with trastuzumab, the median PFS was 10.4 months in the control group and 16.9 months in the pertuzumab group (HR: 0.62; 95\% Cl: 0.35-1.07), with no significant benefit. In patients who did not receive trastuzumab therapy, the median PFS was 12.6 months in the control group and 21.6 months in the pertuzumab group (HR: $0.60 ; 95 \% \mathrm{Cl}: 0.43-0.83$ ), with a statistically benefit [27]. The number of patients who received adjuvant chemotherapy with trastuzumab in the CLEOPATRA trial was smaller than those in the PHEREXA trial. The dual HER2 inhibition yielded nonsignificant benefit in PFS (HR: 0.82; 95\% Cl: 0.65-1.02) compared with PHC with HC [11]. PHEREXA trial reported an improvement in OS (from 28.1 months to 37.2 months) compared with those observed in other studies on patients who experienced progression after trastuzumab treatment $[12,22]$. The inconsistency between modest PFS and increase OS effect was unclear and should not undermine the importance of OS result in the network analysis. Just as the ASCO suggested, the trastuzumab/pertuzumab combination remains the first-line treatment and T-DM1 as the second-line treatment because of its negative effects on PFS $[28,29]$.

Our results showed that T-DM1 showed better PFS and ORR than other regimens. In the included EMILIA study, T-DM1 significantly prolonged the PFS and OS of HER2-positive breast cancer patients previously treated with trastuzumab compared with lapatinib plus capecitabine [12]. T-DM1 should be used as an alternative therapy for patients who are heavily treated with trastuzumab as recommended by the National Comprehensive Cancer Network Panel [30]. In the indirect comparison, T-DM1 demonstrated superior PFS (HR: $0.65 ; 95 \% \mathrm{Cl}$ : 0.46-0.93) and ORR (JR: 3.85; 95\% Cl: 1.92-7.69) compared with $\mathrm{HC}$ and an increasing ORR compared with PHC. In the MARIANNE study, T-DM1 plus pertuzumab did not show any improvement in OS compared with trastuzumab plus taxane as first-line treatment for HER2-positive 
advanced breast cancer [31]. The PFS for T-DM1 alone was also non-inferior to that of trastuzumab plus taxane [31].

There were discrepancies in the results of previous studies that evaluated the effects of tyrosine kinase inhibitors (TKIs; neratinib and afatinib) as an alternative regimen. Neratinib is an oral irreversible panErbB receptor TKI, while afatinib is an irreversible HER1 and HER2 inhibitor [32]. The EGF104900 trial compared trastuzumab plus lapatinib with lapatinib as treatment for MBC patients who previously received trastuzumab and indicated the synergistic effect of these regimens on the PFS and OS of both treatment groups $[25,26]$. Regrettably, the dual HER2 inhibition with trastuzumab plus lapatinib was not included in the network analysis, as no direct comparison was made between this regimen and other regimens. It may be feasible to perform an NMA; however, in a traditional meta-analysis of the efficiency of trastuzumab-based therapy versus non trastuzumab-based therapy, all regimens were included to increase the feasibility of the present NMA. In the latest ASCO Annual Meeting, a biomarker analysis from EGF104900 showed that subtype defined by PAM50 and HER2/neu mRNA expression had a higher response rate and longer PFS and OS [29,33]. The use of trastuzumab plus neratinib showed a $27 \%$ ORR in 33 patients with advanced breast cancer who were previously treated with trastuzumab [34,35]. Oral neratinib showed substantial clinical activity, with a significant clinical activity (ORR: $24 \%$ ) and 59\% 16week PFS rates among patients who previously received trastuzumab treatment [36]. In the two-arm study, neratinib was neither inferior nor non-inferior to lapatinib plus capecitabine [23]. According to the network-analysis results, it is essential to identify which clinical subsets of patients are the best beneficiaries.

The study provides insight into the treatment of patients with metastatic HER2-positive breast cancer progression who were previously treated with trastuzumab, using a Bayesian statistical model. Some limitations of the study should be acknowledged. First, all included studies were open-label studies; although no significant bias was detected by the Review Manager, this finding will not improve the reliability of our study. Second, the data were extracted from published studies, which may have resulted in publication and reporting bias. Third, the estrogen receptor status in some studies was indistinct, and the biological differences may affect the prognosis, although endocrine therapy and immunotherapeutic agent were excluded. Fourth, we mainly focused on patients previously treated trastuzumab-based therapy who experienced progression, omitting pertuzumab and other HER2-target regimens relevant to the progression, as some of them are used in the clinical practice. Hence, caution must be taken when extrapolating the results of patients previously treated with pertuzumab and other HER2-target regimens. Finally, we had no access to patients' data on the mechanism of drug resistance and prognosis of molecular and subgroups. Thus, it was hard to identify which clinical subsets of patients are most likely to benefit from alternative treatment.

\section{Conclusions}

This NMA showed that the continued use of trastuzumab with another type of chemotherapy remains a better option for patients previously treated with trastuzumab-based therapy who experienced 
progression. The degree of benefit may depend on the time of progression and the mechanism of resistance, which should be further explored. Patients treated with PHC will more likely exhibit an improvement in OS. Moreover, patients treated with T-DM1 showed better PFS and ORR than those treated with other regimens. In general, these two therapeutic regimens are indistinguishable and require further evaluation using larger head-to-head clinical trial validation and elaborate subgroup analysis.

\section{Abbreviations}

HER2: human epidermal growth factor receptor 2; MBC: metastatic breast cancer; RCTs: randomized controlled trials; HR: hazard ratio; OS: overall survival; SUCRA: surface under the cumulative ranking; ORR: objective response rate; PFS: progression-free survival; Cls: confidence intervals; NMA: network metaanalysis; DIC: deviance information criteria; LC: lapatinib plus capecitabine; HC: trastuzumab plus capecitabine; PHC: pertuzumab and trastuzumab plus capecitabine; LV: lapatinib plus vinorelbine; T-DM1: trastuzumab emtansine; $\mathrm{HV}$ : trastuzumab plus vinorelbine; $\mathrm{AV}$ : afatinib plus vinorelbine; $\mathrm{HL}$ : lapatinib plus trastuzumab; IFs: inconsistency factors.

\section{Declarations}

\section{Ethics approval and consent to participate}

Not applicable

\section{Consent for publication}

Not applicable

\section{Availability of data and materials}

All data generated or analysed during this study are included in this published article.

\section{Competing interests}

The authors declare that they have no competing interests

\section{Funding}

This study was supported by grants from National Science Foundation of China (nos. 81473513 and 81673799). The sponsors did not play a role in the article publication.

\section{Authors Contributions}

CGS, FBF and TTZ conceived and designed the study; FBF, FY, LYQ, XW and JHT performed data analysis; $\mathrm{CL}, \mathrm{JZ}$ and FBF contributed analysis tools; FBF and CGS wrote the paper. 
Acknowledgments

Not applicable

\section{References}

[1] Dawood S, Broglio K, Buzdar AU, et al. Prognosis of women with metastatic breast cancer by HER2 status and trastuzumab treatment: an institutional-based review. J Clin Oncol. 2010; 28: 92-98.

[2] Ross JS, Slodkowska EA, Symmans WF, et al. The HER-2 receptor and breast cancer: Ten years of targeted anti-HER-2 therapy and personalized medicine. Oncologist. 2009; 14: 320-368.

[3] Slamon DJ, Leyland-Jones B, Shak S, et al. Use of chemotherapy plus a monoclonal antibody against HER2 for metastatic breast cancer that overexpresses HER2. N Engl J Med. 2001; 344: 783-792.

[4] Perez EA, Romond EH, Suman VJ, et al. Trastuzumab plus adjuvant chemotherapy for human epidermal growth factor receptor 2-positive breast cancer: planned joint analysis of overall survival from NSABP B-31 and NCCTG N9831. J Clin Oncol. 2014; 32(33): 3744-3752.

[5] Marty M, Cognetti F, Maraninchi D, et al. Randomized phase II trial of the efficacy and safety of trastuzumab combined with docetaxel in patients with human epidermal growth factor receptor 2-positive metastatic breast cancer administered as first-line treatment: the M77001 Study Group. J Clin Oncol. 2005; 23: 4265-4274.

[6] Oakman C, Sapino A, Marchiò C, et al. Chemotherapy with or without trastuzumab.[J]. Ann Oncol. 2010; 21 Suppl 7: vii112-9.

[7] Andersson M, Lidbrink E, Bjerre K, et al. Phase III randomized study comparing docetaxel plus trastuzumab with vinorelbine plus trastuzumab as fi rst-line therapy of metastatic or locally advanced human epidermal growth factor receptor 2-positive breast cancer: the HERNATA study. J Clin Oncol. 2011; 29: 264-271.

[8] Awada A, Colomer R, Inoue K, et al. Neratinib plus paclitaxel vs trastuzumab plus paclitaxel in previously untreated metastatic ERBB2-positive breast cancer: the NEfERT-T randomized clinical trial. JAMA Oncol. 2016; 2(12): 1557-1564.

[9] Swain SM, Baselga J, Kim SB, et al. Pertuzumab, trastuzumab, and docetaxel in HER2-positive metastatic breast cancer. N Engl J Med. 2015; 372: 724-734.

[10] Minckwitz G, du Bois A, Schmidt M, et al. Trastuzumab beyond progression in human epidermal growth factor receptor 2-positive advanced breast cancer: a german breast group 26/breast international group 03-05 study. J Clin Oncol. 2009; 27(12): 1999-2006. 
[11] Urruticoechea A, Rizwanullah M, Im SA, et al. Randomized phase III trial of trastuzumab plus capecitabine with or without pertuzumab in patients with human epidermal growth factor receptor 2positive metastatic breast cancer who experienced disease progression during or after trastuzumabbased therapy. J Clin Oncol. 2017; 35(26): 3030-3038.

[12] Verma S, Miles D, Gianni L, et al. Trastuzumab emtansine for HER2-positive advanced breast cancer. N Engl J Med. 2012; 367(19): 1783-1791.

[13] Harbeck N, Huang CS, Hurvitz S, et al. Afatinib plus vinorelbine versus trastuzumab plus vinorelbine in patients with HER2-overexpressing metastatic breast cancer who had progressed on one previous trastuzumab treatment (LUX-Breast 1): an open-label, randomised, phase 3 trial. The lancet Oncology. 2016; 17(3): 357-366.

[14] Moher D, Liberati A, Tetzlaff J, et al. Preferred reporting items for systematic reviews and metaanalyses: the PRISMA statement. BMJ. 2009; 339: b2535.

[15] Higgins JP, Altman DG, Gotzsche PC, Juni P, Moher D, Oxman AD, et al. The Cochrane Collaboration's tool for assessing risk of bias in randomised trials. BMJ 2011; 343: d5928.

[16] Higgins JP, Thompson SG, Deeks JJ, et al. Measuring inconsistency in meta-analyses. BMJ. 2003; 327(7414): 557-60.

[17] Chaimani A, Higgins JP, Mavridis D, et al. Graphical tools for network meta-analysis in STATA. PLoS One. 2013; 8(10): e76654.

[18] Rucker G, Schwarzer G. Ranking treatments in frequentist network meta-analysis works without resampling methods. BMC Med Res Methodol. 2015; 15: 58.

[19] Lu G, Ades AE. Combination of direct and indirect evidence in mixed treatment comparisons. Stat Med. 2004; 23(20): 3105-3124.

[20] Trinquart L, Chatellier G, Ravaud P. Adjustment for reporting bias in network meta-analysis of antidepressant trials. BMC Med Res Methodol. 2012; 12(1): 150.

[21] Takano T, Tsurutani J, Takahashi M, et al. A randomized phase II trial of trastuzumab plus capecitabine versus lapatinib plus capecitabine in patients with HER2-positive metastatic breast cancer previously treated with trastuzumab and taxanes: WJOG6110B/ELTOP. Breast. 2018; 40: 67-75.

[22] Janni W, Sarosiek T, Karaszewska B, et al. A phase II, randomized, multicenter study evaluating the combination of lapatinib and vinorelbine in women with ErbB2 overexpressing metastatic breast cancer. Breast Cancer Res Treat. 2014; 143(3): 493-505.

[23] Martin M, Bonneterre J, Geyer CE, et al. A phase two randomised trial of neratinib monotherapy versus lapatinib plus capecitabine combination therapy in patients with HER2+ advanced breast cancer. 
Eur J Cancer. 2013; 49(18): 3763-3772.

[24] Geyer CE, Forster J, Lindquist D, et al. Lapatinib plus capecitabine for HER2-positive advanced breast cancer. N Engl J Med 2006; 355(26): 2733-2743.

[25] Blackwell KL, Burstein HJ, Storniolo AM, et al. Overall survival benefit with lapatinib in combination with trastuzumab for patients with human epidermal growth factor receptor 2-positive metastatic breast cancer: final results from the EGF104900 Study. J Clin Oncol. 2012; 30(21): 2585-2592.

[26] Blackwell KL, Burstein HJ, Storniolo AM, et al. Randomized study of Lapatinib alone or in combination with trastuzumab in women with ErbB2-positive, trastuzumab-refractory metastatic breast cancer. J Clin Oncol. 2010; 28(7): 1124-1130.

[27] Baselga J, Cortes J, Kim SB, et al. Pertuzumab plus trastuzumab in metastatic breast cancer.[J]. N Engl J Med. 2011; 366(2): 109-119.

[28] Dzimitrowicz H, Berger M, Vargo C, et al. T-DM1 activity in metastatic human epidermal growth factor receptor 2-positive breast cancers that received prior therapy with trastuzumab and pertuzumab. J Clin Oncol. 2016; 34(29): 3511-3517

[29] Bartsch R, Bergen E. ASCO 2018: highlights in HER2-positive metastatic breast cancer. Memo. 2018; 11(4): 280-283.

[30] National Comprehensive Cancer Network (2018) NCCN Clinical practice guidelines in oncology: breast cancer. Version 3.2018. http://www.nccn.org /professionals/physician_gls/PDF /breast.pdf

[31] Perez EA, Barrios C, Eiermann W, et al. Trastuzumab Emtansine With or Without Pertuzumab Versus Trastuzumab Plus Taxane for Human Epidermal Growth Factor Receptor 2-Positive, Advanced Breast Cancer: Primary Results From the Phase III MARIANNE Study. J Clin Oncol. 2017; 35(2):141-148.

[32] Lin NU, Winer EP, Wheatley D, et al. A phase II study of afatinib (BIBW 2992), an irreversible ErbB family blocker, in patients with HER2-positive metastatic breast cancer progressing after trastuzumab. Breast Cancer Res Treat. 2012; 133(3): 1057-65.

[33] Pascual T, Pare L, Galvan P et al. PAM50 HER2-enriched/ERBB2-high (HER2-E/ERBB2H) biomarker to predict response and survival following lapatinib $(L)$ alone or in combination with trastuzumab $(T)$ in HER2+ T-refractory metastatic breast cancer (BC): A correlative analysis of the EGF104900 phase III trial. J Clin Oncol. 2018; 36(Suppl.15): Abst. 1025.

[34] Swaby R, Blackwell KL, Jiang Z, et al. Neratinib in combination with trastuzumab for the treatment of advanced breast cancer: A phase I/II study. J Clin Oncol. 27: 15s, 2009 (suppl; abstr 1004)

[35] Saura C, Garcia-Saenz JA, Xu B, et al. Safety and Efficacy of Neratinib in Combination With Capecitabine in Patients With Metastatic Human Epidermal Growth Factor Receptor 2-Positive Breast 
Cancer. J Clin Oncol. 2014: 32(32): 3626-3633.

[36] Burstein HJ, Sun Y, Dirix LY, et al. Neratinib, an irreversible ErbB receptor tyrosine kinase inhibitor, in patients with advanced ErbB2-positive breast cancer. J Clin Oncol. 2010; 28: 1301-1307.

\section{Tables}

Table 1: Characteristics of studies that were included in the meta-analysis 


\begin{tabular}{|c|c|c|c|c|c|c|c|c|c|c|}
\hline $\begin{array}{l}\text { Study } \\
\text { number }\end{array}$ & First author & Year & $\begin{array}{l}\text { Interventions } \\
\text { compared }\end{array}$ & Arm & $\mathrm{n}(\mathrm{A} / \mathrm{B})$ & $\begin{array}{l}\text { Mean or } \\
\text { median } \\
\text { age }(y r)\end{array}$ & $\begin{array}{c}\text { HR } \\
\text { status } \\
(\%)\end{array}$ & $\begin{array}{c}\text { Primary } \\
\text { objectives }\end{array}$ & $\begin{array}{l}\text { Median } \\
\text { PFS/TTP } \\
\text { (months) }\end{array}$ & Outcome \\
\hline \multirow[t]{2}{*}{1} & \multirow[t]{2}{*}{ Takano } & \multirow[t]{2}{*}{2018} & \multirow{2}{*}{$\begin{array}{l}\text { Arm A: } \\
\text { trastuzumab } \\
\text { and } \\
\text { capecitabine; } \\
\text { Arm B: lapatinib } \\
\text { (1250 mg/day) } \\
\text { and } \\
\text { capecitabine }\end{array}$} & $\begin{array}{l}\text { Arm } \\
\text { A }\end{array}$ & 43 & $\begin{array}{l}57(34- \\
81)\end{array}$ & $\begin{array}{l}\text { Er+ } \\
\text { and/or } \\
\text { Pr+63\% }\end{array}$ & \multirow[t]{2}{*}{ PFS } & 6.1 & \multirow[t]{2}{*}{$\begin{array}{l}\text { PFS/OS } \\
\text { /ORR }\end{array}$} \\
\hline & & & & $\begin{array}{l}\text { Arm } \\
\text { B }\end{array}$ & 43 & $\begin{array}{l}59(37- \\
78)\end{array}$ & $\begin{array}{l}\text { Er+ } \\
\text { and/or } \\
\text { Pr+63\% }\end{array}$ & & 7.1 & \\
\hline \multirow[t]{2}{*}{2} & \multirow[t]{2}{*}{ Urruticoechea } & \multirow[t]{2}{*}{2017} & \multirow{2}{*}{$\begin{array}{l}\text { Arm A: } \\
\text { trastuzumab } \\
\text { and } \\
\text { capecitabine } \\
\text { Arm B: } \\
\text { pertuzumab , } \\
\text { trastuzumab } \\
\text { and } \\
\text { capecitabine }\end{array}$} & $\begin{array}{l}\text { Arm } \\
\text { A }\end{array}$ & 224 & 55 & $\begin{array}{l}\text { Er+ } \\
\text { and/or } \\
\text { Pr+ } \\
55.0 \%\end{array}$ & \multirow[t]{2}{*}{$\begin{array}{l}(\text { IRF }) \\
\text { PFS }\end{array}$} & 9.0 & \multirow[t]{2}{*}{$\begin{array}{l}\text { PFS/OS } \\
\text { /ORR }\end{array}$} \\
\hline & & & & $\begin{array}{l}\text { Arm } \\
\text { B }\end{array}$ & 228 & 54 & $\begin{array}{l}\text { Er+ } \\
\text { and/or } \\
\text { Pr+ } \\
55.0 \%\end{array}$ & & 11.1 & \\
\hline \multirow[t]{2}{*}{3} & \multirow[t]{2}{*}{ Harbeck } & \multirow[t]{2}{*}{2016} & \multirow{2}{*}{$\begin{array}{l}\text { Arm A: afatinib } \\
\text { and vinorelbine } \\
\text { Arm B: } \\
\text { trastuzumab } \\
\text { and vinorelbine }\end{array}$} & $\begin{array}{l}\text { Arm } \\
\text { A }\end{array}$ & 339 & 51.8 & $\begin{array}{l}\text { Er+ } \\
48 \% \\
\operatorname{Pr}+34 \%\end{array}$ & \multirow[t]{2}{*}{ PFS } & 5.5 & \multirow[t]{2}{*}{$\begin{array}{l}\mathrm{PFS} / \mathrm{OS} \\
\text { /ORR }\end{array}$} \\
\hline & & & & $\begin{array}{l}\text { Arm } \\
\text { B }\end{array}$ & 169 & 53.1 & $\begin{array}{l}\text { Er+ } \\
48 \% \\
\operatorname{Pr}+30 \%\end{array}$ & & 5.6 & \\
\hline \multirow[t]{2}{*}{4} & \multirow[t]{2}{*}{ Janni } & \multirow[t]{2}{*}{2014} & \multirow{2}{*}{$\begin{array}{l}\text { Arm A: lapatinib } \\
\text { plus vinorelbine } \\
\text { Arm B: } \\
\text { lapatinib plus } \\
\text { capecitabine }\end{array}$} & $\begin{array}{l}\text { Arm } \\
\text { A }\end{array}$ & 75 & $\begin{array}{l}57(32- \\
79)\end{array}$ & $\begin{array}{l}\text { Er+ } \\
49 \% \\
\operatorname{Pr}+33 \%\end{array}$ & \multirow[t]{2}{*}{ PFS } & 6.2 & \multirow[t]{2}{*}{$\begin{array}{l}\text { PFS/OS } \\
\text { /ORR }\end{array}$} \\
\hline & & & & $\begin{array}{l}\text { Arm } \\
\text { B }\end{array}$ & 37 & $\begin{array}{l}58(36- \\
83)\end{array}$ & $\begin{array}{l}\text { Er+ } \\
51 \% \\
\operatorname{Pr}+38 \% \\
\end{array}$ & & 6.2 & \\
\hline \multirow[t]{2}{*}{5} & \multirow[t]{2}{*}{ Martin } & \multirow[t]{2}{*}{2013} & \multirow{2}{*}{$\begin{array}{l}\text { Arm A: } \\
\text { neratinib orally } \\
\text { at a dose of } 240 \\
\mathrm{mg} / \mathrm{d} \\
\text { Arm B: } \\
\text { lapatinib plus } \\
\text { capecitabine }\end{array}$} & $\begin{array}{l}\text { Arm } \\
\text { A }\end{array}$ & 117 & $\begin{array}{l}52(28- \\
79)\end{array}$ & $\begin{array}{l}\text { Er+ } \\
44 \% \\
\operatorname{Pr}+27 \%\end{array}$ & \multirow[t]{2}{*}{ PFS } & 4.5 & \multirow[t]{2}{*}{$\begin{array}{l}\text { PFS/OS } \\
\text { /ORR }\end{array}$} \\
\hline & & & & $\begin{array}{l}\text { Arm } \\
\text { B }\end{array}$ & 116 & $\begin{array}{l}56(30- \\
79)\end{array}$ & $\begin{array}{l}\text { Er+ } \\
40 \% \\
\operatorname{Pr}+28 \%\end{array}$ & & 6.8 & \\
\hline \multirow[t]{2}{*}{6} & \multirow[t]{2}{*}{ Verma } & \multirow[t]{2}{*}{2012} & \multirow{2}{*}{$\begin{array}{l}\text { Arm A: lapatinib } \\
\text { plus } \\
\text { capecitabine } \\
\text { Arm B: T-DM1 }\end{array}$} & $\begin{array}{l}\text { Arm } \\
\text { A }\end{array}$ & 496 & $\begin{array}{l}53(24- \\
83)\end{array}$ & $\begin{array}{l}\text { Er+ } \\
\text { and/or } \\
\operatorname{Pr}+53 \%\end{array}$ & \multirow[t]{2}{*}{$\begin{array}{l}\text { (IRF) } \\
\text { PFS }\end{array}$} & 6.4 & \multirow[t]{2}{*}{$\begin{array}{l}\text { PFS/OS } \\
\text { /ORR }\end{array}$} \\
\hline & & & & $\begin{array}{l}\text { Arm } \\
\text { B }\end{array}$ & 495 & $\begin{array}{l}53(25- \\
84)\end{array}$ & $\begin{array}{l}\text { Er+ } \\
\text { and/or } \\
\text { Pr+ 57\% }\end{array}$ & & 9.6 & \\
\hline 7 & Blackwell & 2012 & $\begin{array}{l}\text { Arm A: lapatinib } \\
\text { monotherapy } \\
\text { Arm B: }\end{array}$ & $\begin{array}{l}\text { Arm } \\
\text { A }\end{array}$ & 148 & $\begin{array}{l}51(29- \\
78)\end{array}$ & $\begin{array}{l}\text { ER and } \\
\text { PgR- } \\
51 \%\end{array}$ & PFS & 1.89 & OS \\
\hline & & & $\begin{array}{l}\text { lapatinib plus } \\
\text { trastuzumab }\end{array}$ & $\begin{array}{l}\text { Arm } \\
\text { B }\end{array}$ & 148 & $\begin{array}{l}52(26- \\
81)\end{array}$ & $\begin{array}{l}\text { ER and } \\
\text { PgR- }\end{array}$ & & 2.8 & \\
\hline
\end{tabular}




\begin{tabular}{|c|c|c|c|c|c|c|c|c|c|c|}
\hline & & & & & & & $51 \%$ & & & \\
\hline \multirow[t]{2}{*}{8} & \multirow[t]{2}{*}{ Blackwell } & \multirow[t]{2}{*}{2010} & \multirow{2}{*}{$\begin{array}{l}\text { Arm A: lapatinib } \\
\text { monotherapy } \\
\text { Arm B: } \\
\text { lapatinib plus } \\
\text { trastuzumab }\end{array}$} & $\begin{array}{l}\text { Arm } \\
\text { A }\end{array}$ & 148 & $\begin{array}{l}51(29- \\
78)\end{array}$ & $\begin{array}{l}\text { ER and } \\
\text { PgR- } \\
51 \% \\
\end{array}$ & \multirow[t]{2}{*}{ PFS } & 1.89 & \multirow[t]{2}{*}{ PFS/ORR } \\
\hline & & & & $\begin{array}{l}\text { Arm } \\
\text { B }\end{array}$ & 148 & $\begin{array}{l}52(26- \\
81)\end{array}$ & $\begin{array}{l}\text { ER and } \\
\text { PgR- } \\
51 \% \\
\end{array}$ & & 2.8 & \\
\hline \multirow[t]{2}{*}{9} & \multirow[t]{2}{*}{ Minckwitz } & \multirow[t]{2}{*}{2009} & \multirow{2}{*}{$\begin{array}{l}\text { Arm A: } \\
\text { capecitabine } \\
\text { monotherapy } \\
\text { Arm B: } \\
\text { capecitabine } \\
\text { plus } \\
\text { trastuzumab }\end{array}$} & $\begin{array}{l}\text { Arm } \\
\text { A }\end{array}$ & 78 & $\begin{array}{l}59.0(33- \\
82)\end{array}$ & $\begin{array}{l}\text { Er+ } \\
\text { and/or } \\
\operatorname{Pr}+62 \%\end{array}$ & \multirow[t]{2}{*}{ TTP } & 5.6 & \multirow[t]{2}{*}{$\begin{array}{l}\text { TTP//OS } \\
\text { /ORR }\end{array}$} \\
\hline & & & & $\begin{array}{l}\text { Arm } \\
\text { B }\end{array}$ & 78 & $\begin{array}{l}52.5(28- \\
78)\end{array}$ & $\begin{array}{l}\text { Er+ } \\
\text { and/or } \\
\text { Pr+ 56\% }\end{array}$ & & 8.2 & \\
\hline \multirow[t]{2}{*}{10} & \multirow[t]{2}{*}{ Geyer } & \multirow[t]{2}{*}{2006} & \multirow{2}{*}{$\begin{array}{l}\text { Arm A: lapatinib } \\
\text { plus } \\
\text { capecitabine } \\
\text { Arm B: } \\
\text { capecitabine } \\
\text { monotherapy }\end{array}$} & $\begin{array}{l}\text { Arm } \\
\text { A }\end{array}$ & 163 & $\begin{array}{l}54(26- \\
80 \square\end{array}$ & $\begin{array}{l}\text { Er+ } \\
\text { and/or } \\
\text { Pr+ 48\% }\end{array}$ & \multirow[t]{2}{*}{ TTP } & 8.4 & \multirow[t]{2}{*}{$\begin{array}{l}\text { TTP/OS } \\
\text { /ORR }\end{array}$} \\
\hline & & & & $\begin{array}{l}\text { Arm } \\
\text { B }\end{array}$ & 161 & $\begin{array}{l}51(28- \\
83)\end{array}$ & $\begin{array}{l}\text { Er+ } \\
\text { and/or } \\
\operatorname{Pr}+47 \%\end{array}$ & & 4.4 & \\
\hline
\end{tabular}

Abbreviations: PFS: progression-free survival; (IRF)PFS: independent review facility-assessed progression-free survival; TTP: Time to progression; OS:overall survival; ORR, objective response rate; $\mathrm{Er}+$, estrogen receptor-positive; $\mathrm{PR}+$, progesterone receptor-positive.

Table2A. Network meta-analysis for PFS (lower triangle) and OS (upper triangle) Table2B. Network metaanalysis for OR (lower triangle) 


\begin{tabular}{|c|c|c|c|c|c|c|}
\hline LC & $\begin{array}{c}1.39 \\
(0.83-2.32)\end{array}$ & $\begin{array}{c}2.04 \\
(1.14-3.66)\end{array}$ & $\begin{array}{c}0.98 \\
(0.48-1.99)\end{array}$ & $\begin{array}{c}0.80 \\
(0.53-1.20)\end{array}$ & $\begin{array}{c}1.47 \\
(1.18-1.83)\end{array}$ & $\begin{array}{c}0.99 \\
(0.65-1.50)\end{array}$ \\
\hline $\begin{array}{c}1.00 \\
(0.73-1.37)\end{array}$ & $\mathrm{HC}$ & \begin{tabular}{|c|}
1.47 \\
$(1.11-1.95)$
\end{tabular} & $\begin{array}{c}0.71 \\
(0.30-1.69)\end{array}$ & $\begin{array}{c}0.57 \\
(0.30-1.10)\end{array}$ & $\begin{array}{c}1.06 \\
(0.61-1.85)\end{array}$ & $\begin{array}{c}0.71 \\
(0.47-1.08)\end{array}$ \\
\hline $\begin{array}{c}1.22 \\
(0.83-1.80)\end{array}$ & $\begin{array}{c}1.22 \\
(0.97-1.54)\end{array}$ & PHC & $\begin{array}{c}0.48 \\
(0.19-1.20)\end{array} \mid$ & $\begin{array}{c}0.39 \\
(0.20-0.80)\end{array}$ & $\begin{array}{c}0.72 \\
(0.39-1.34)\end{array}$ & $\begin{array}{c}0.48 \\
(0.29-0.80)\end{array}$ \\
\hline $\begin{array}{c}1.19 \\
(0.75-1.90)\end{array}$ & $\begin{array}{c}1.19 \\
(0.68-2.08)\end{array}$ & $\begin{array}{c}0.97 \\
(0.53-1.78)\end{array}$ & LV & $\begin{array}{c}0.82 \\
(0.36-1.84)\end{array}$ & $\begin{array}{c}1.50 \\
(0.71-3.14)\end{array}$ & $\begin{array}{c}1.01 \\
(0.44-2.28)\end{array}$ \\
\hline $\begin{array}{c}0.84 \\
(0.63-1.13)\end{array}$ & $\begin{array}{c}0.84 \\
(0.55-1.28)\end{array}$ & $\mid \begin{array}{c}0.69 \\
(0.42-1.11)\end{array}$ & $\left|\begin{array}{c}0.70 \\
(0.41-1.22)\end{array}\right|$ & Neratinib & $\begin{array}{c}1.84 \\
(1.16-2.91)\end{array}$ & $\begin{array}{c}1.23 \\
(0.69-2.20)\end{array}$ \\
\hline $\begin{array}{c}1.54 \\
(1.30-1.82)\end{array}$ & $\begin{array}{c}1.53 \\
(1.08-2.19)\end{array}$ & $\mid \begin{array}{c}1.26 \\
(0.83-1.92)\end{array}$ & $\begin{array}{c}1.29 \\
(0.78-2.12)\end{array} \mid$ & $\begin{array}{c}1.83 \\
(1.30-2.57)\end{array}$ & T-DM1 & $\begin{array}{c}0.67 \\
(0.42-1.07)\end{array}$ \\
\hline $\begin{array}{c}0.59 \\
(0.43-0.80)\end{array}$ & $\begin{array}{c}0.59 \\
(0.44-0.78)\end{array}$ & $\begin{array}{c}0.48 \\
(0.33-0.70)\end{array}$ & $\begin{array}{c}0.49 \\
(0.28-0.86)\end{array}$ & $\begin{array}{c}0.70 \\
(0.46-1.06)\end{array}$ & $\begin{array}{c}0.38 \\
(0.27-0.54)\end{array}$ & Capecitabine \\
\hline
\end{tabular}

\begin{tabular}{|c|c|c|c|c|c|c|}
\hline LC & & & & & & \\
\hline $\begin{array}{c}2.25 \\
(1.17-4.30)\end{array}$ & $\mathrm{HC}$ & & & & & \\
\hline $\begin{array}{c}1.62 \\
(0.74-3.56)\end{array}$ & $\begin{array}{c}0.72 \\
(0.46-1.13)\end{array}$ & PHC & & & & \\
\hline $\begin{array}{c}2.18 \\
(0.89-5.36)\end{array}$ & $\begin{array}{c}0.97 \\
(0.32-2.94)\end{array}$ & $\begin{array}{c}1.35 \\
(0.41-4.46)\end{array}$ & LV & & & \\
\hline $\begin{array}{c}1.67 \\
(0.97-2.90)\end{array}$ & $\begin{array}{c}0.74 \\
(0.32-1.73)\end{array}$ & $\begin{array}{c}1.03 \\
(0.39-2.70)\end{array}$ & $\begin{array}{c}0.77 \\
(0.27-2.20)\end{array}$ & Neratinib & & \\
\hline $\begin{array}{c}0.58 \\
(0.43-0.77)\end{array}$ & $\begin{array}{c}0.26 \\
(0.13-0.52)\end{array}$ & $\begin{array}{c}0.36 \\
(0.15-0.83)\end{array}$ & $\begin{array}{c}0.26 \\
(0.10-0.68)\end{array}$ & $\begin{array}{c}0.35 \\
(0.18-0.64)\end{array}$ & T-DM1 & \\
\hline $\begin{array}{c}1.26 \\
(0.76-2.11)\end{array}$ & $\begin{array}{c}0.56 \\
(0.32-0.99)\end{array}$ & $\begin{array}{c}0.78 \\
(0.37-1.63)\end{array}$ & $\begin{array}{c}0.58 \\
(0.21-1.63)\end{array}$ & $\begin{array}{c}0.76 \\
(0.36-1.60)\end{array}$ & $\begin{array}{c}2.19 \\
(1.22-3.95)\end{array}$ & Capecitabine \\
\hline
\end{tabular}


Notes: The PFS, OS, and ORR; HRs; and $95 \%$ confidence intervals $(95 \% \mathrm{Cl})$ of the treatment listed on the left column were compared with those of the treatments listed on the right column. HRs $<1$ favors the left treatment (i.e., LC was more effective than capecitabine in terms of PFS (HR: $0.59,95 \% \mathrm{Cl}: 0.43-0.80$ ). ORs $>1$ favor the left treatment (i.e., the ORs of LC compared with HC were 2.25, which favor LC treatment). Bold font indicates that the comparisons were statistically significant.

Abbreviations: LC, lapatinib plus capecitabine; HC, trastuzumab plus capecitabine; PHC, pertuzumab and trastuzumab plus capecitabine; LV, lapatinib plus vinorelbine; T-DM1, trastuzumab emtansine; HV, trastuzumab plus vinorelbine; $\mathrm{AV}$, afatinib plus vinorelbine; $\mathrm{HL}$, lapatinib plus trastuzumab

Table 3. Treatment ranking (\% probability) and SUCRA values based on PFS, OS, and ORR

\begin{tabular}{|c|c|c|c|c|c|c|c|}
\hline & LC & HC & PHC & LV & Neratinib & T-DM1 & Capecitabine \\
\hline $\begin{array}{c}\text { PFS } \\
\text { SUCRA }\end{array}$ & 45.9 & 43.8 & 73.7 & 66.6 & 24.3 & $\mathbf{9 4 . 9}$ & 0.9 \\
\hline Best probability & 0.0 & 0.0 & 12.5 & 14.3 & 0.0 & $\mathbf{7 3 . 2}$ & 0.0 \\
\hline $\begin{array}{c}\text { OS } \\
\text { SUCRA }\end{array}$ & 33.6 & 66.7 & $\mathbf{9 6 . 2}$ & 34.6 & 12.5 & 75.6 & 30.8 \\
\hline $\begin{array}{c}\text { Best probability } \\
\text { ORR } \\
\text { SUCRA }\end{array}$ & 0.0 & 0.2 & $\mathbf{8 2 . 3}$ & 4.1 & 0.0 & $13.3 \mid$ & 0.0 \\
\hline Best probability & 0.0 & 0.0 & 0.8 & 0.3 & 0.0 & $\mathbf{9 8 . 5}$ & 0.4 \\
\hline
\end{tabular}

Notes: The larger the SUCRA, the higher the ranking. If the SUCRA value of interventions is closer to 100 , it indicates that it is always in first place.

Abbreviations: LC, lapatinib plus capecitabine; $\mathrm{HC}$, trastuzumab plus capecitabine; $\mathrm{PHC}$, pertuzumab and trastuzumab plus capecitabine; LV, lapatinib plus vinorelbine; T-DM1, trastuzumab emtansine

\section{Figures}




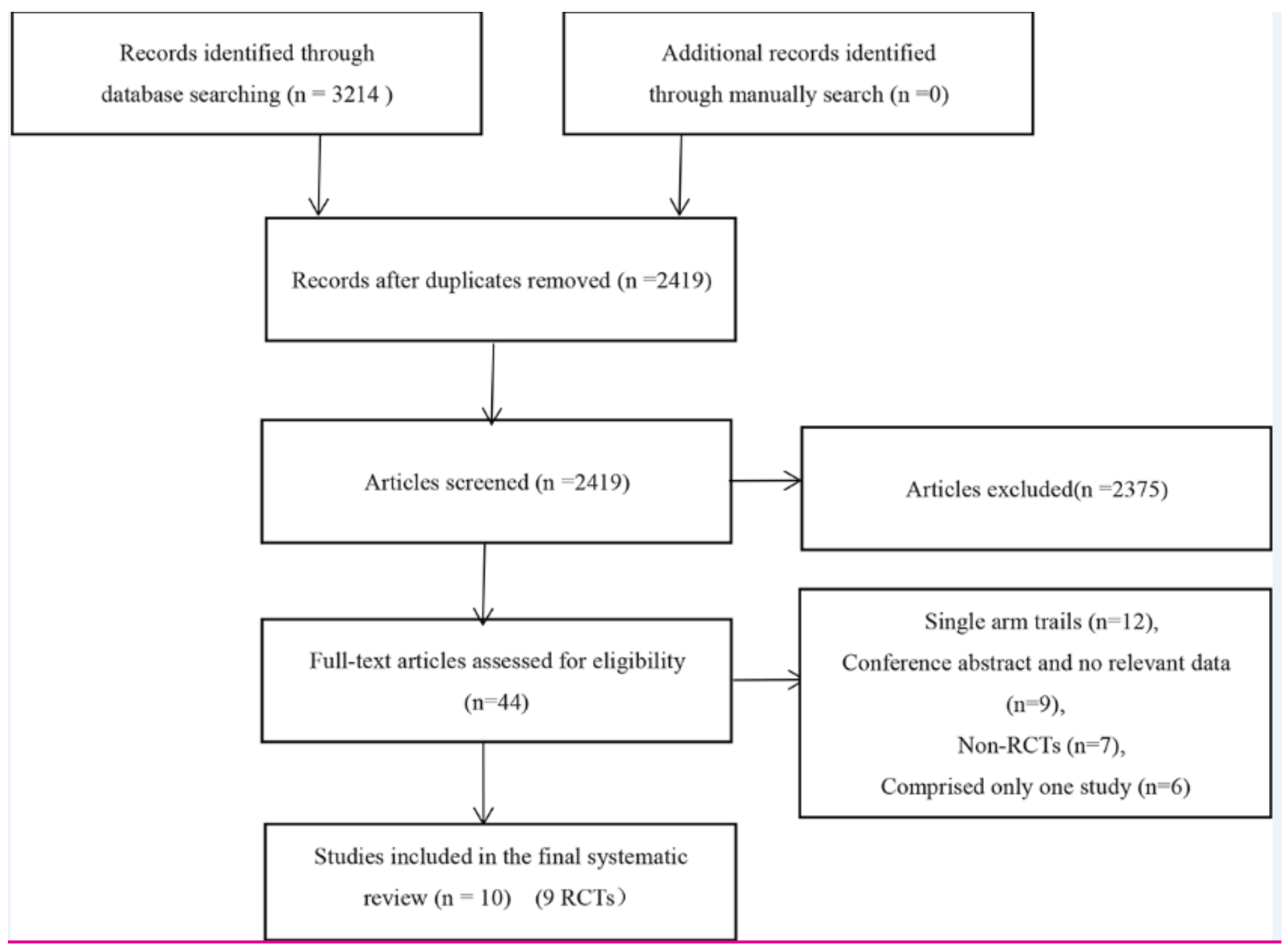

\section{Figure 1}

PRISMA flow diagram of the study selection process 

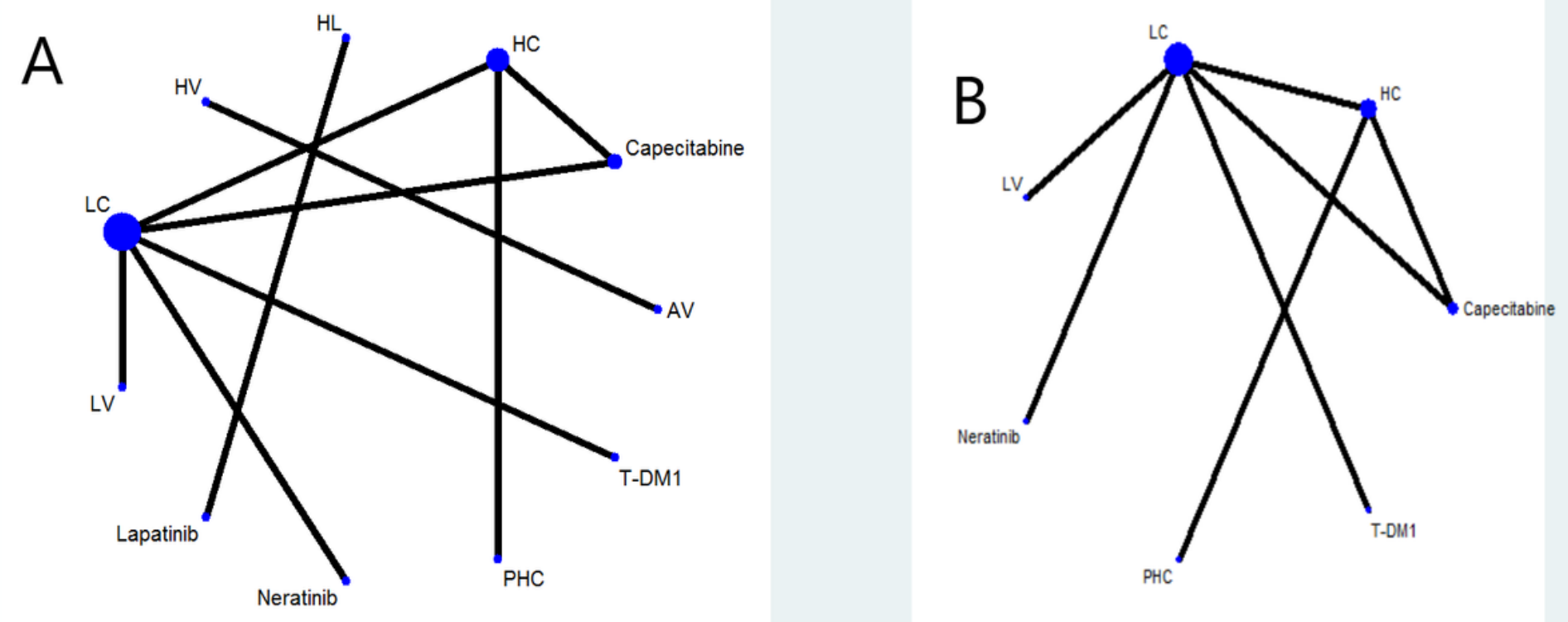

Figure 2

Network diagram of study comparisons for Bayesian network meta-analysis. (A) All included patients; (B) patients included in the network meta-analysis

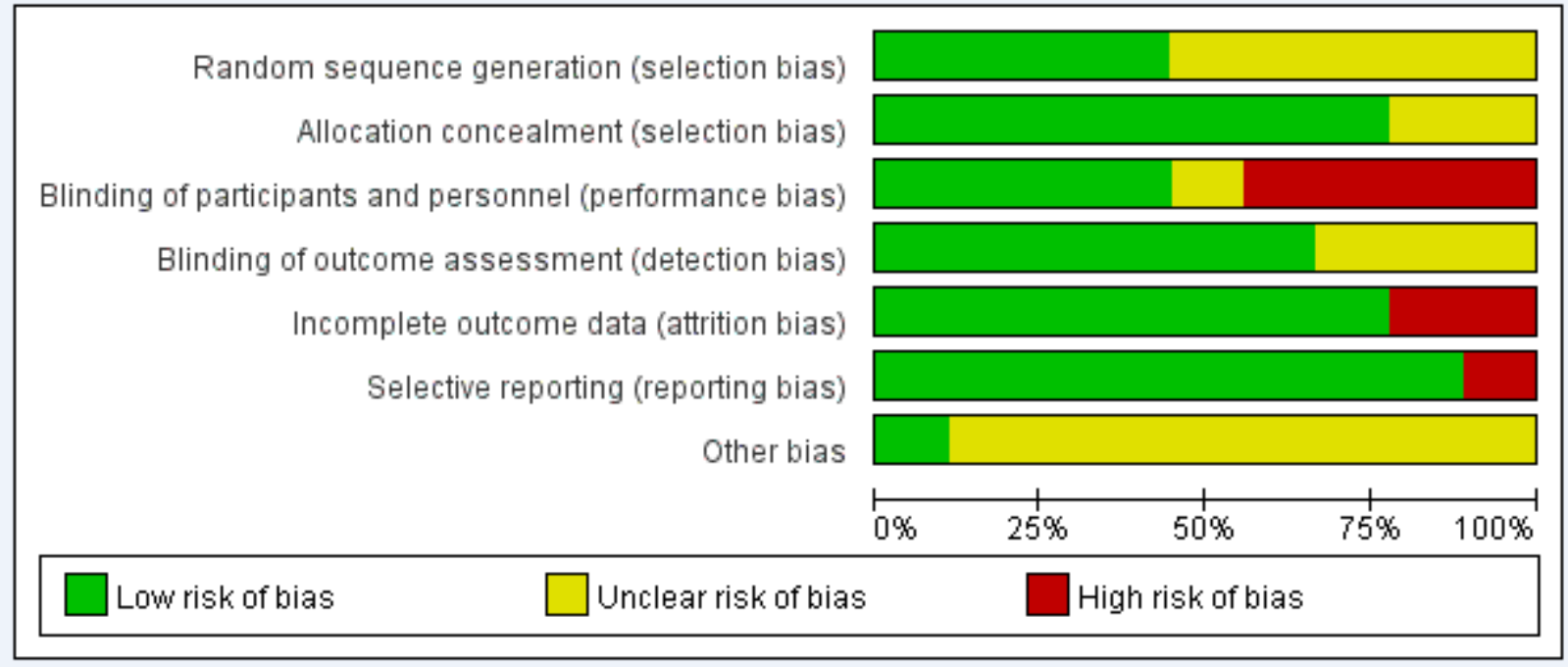

\section{Figure 3}

Cochrane risk of bias tool assessment (+: low risk of bias;:- high risk of bias; and ?: unclear risk of bias) 
A

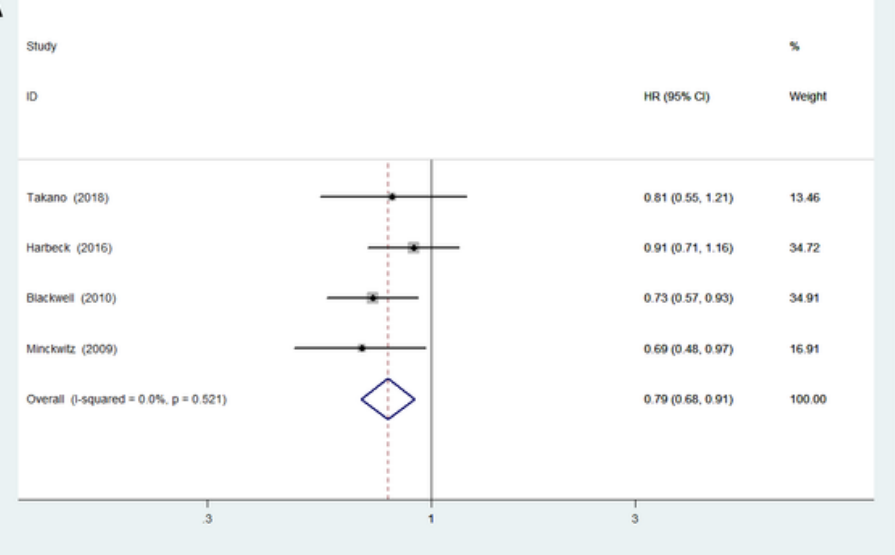

B stuos

10

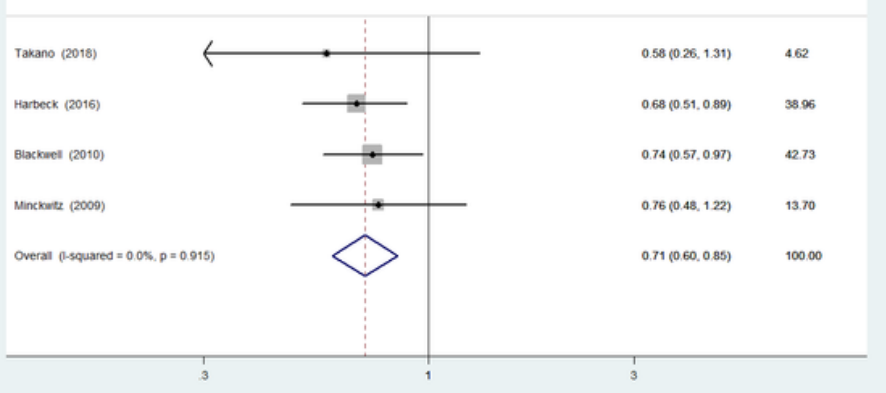

C son
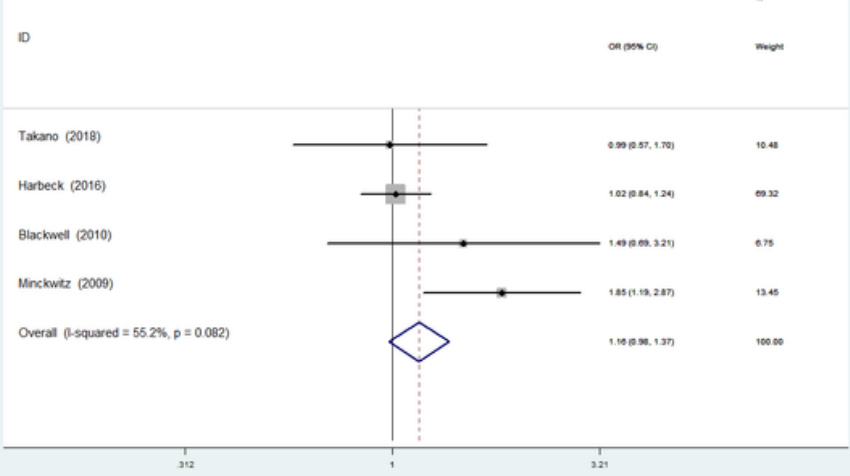

Figure 4

Forest plot of the direct comparison results 
A

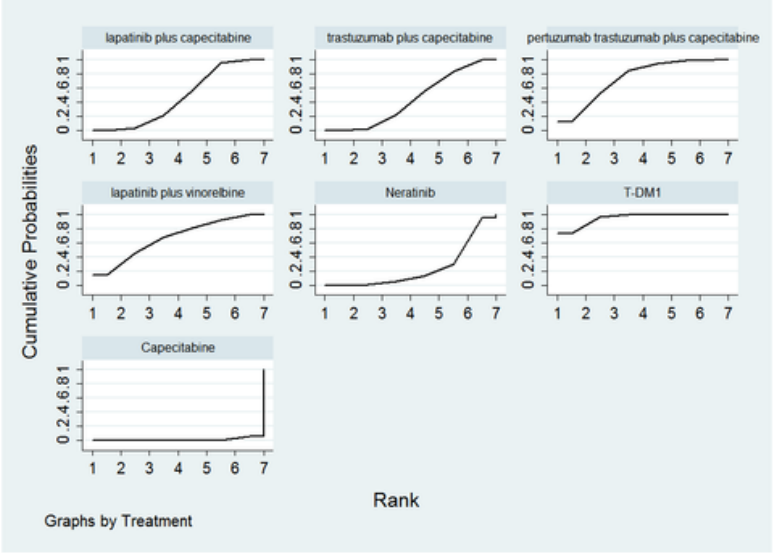

C
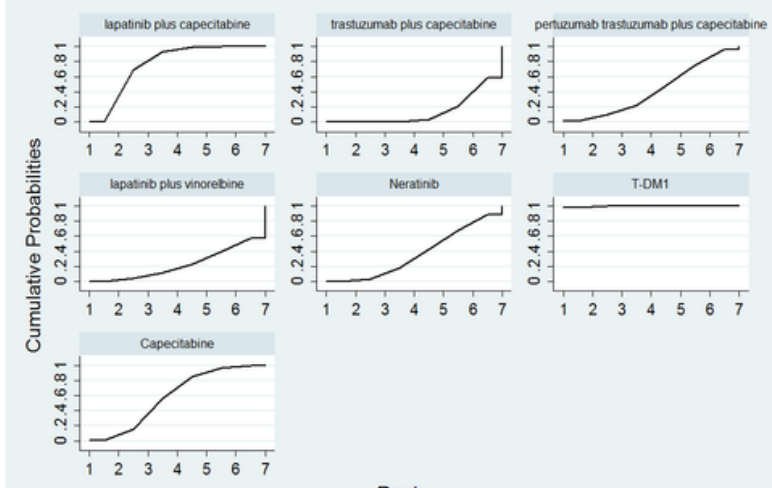

Graphs by Treatment
B

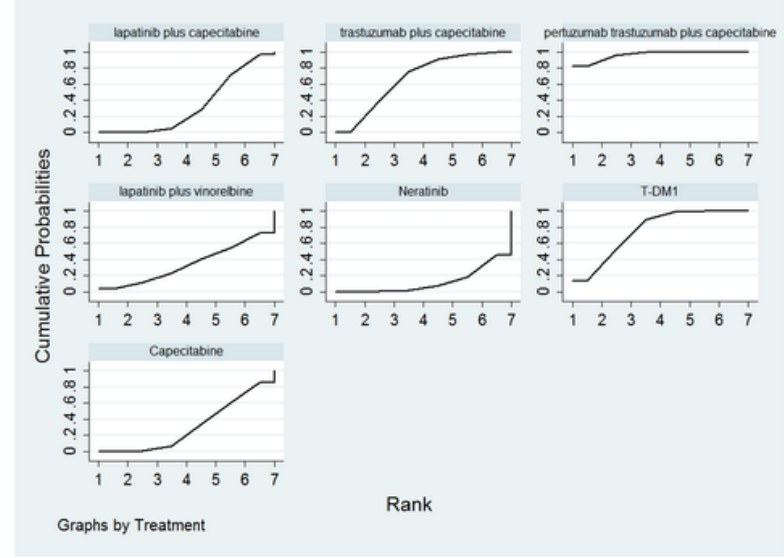

\section{Figure 5}

The surface under the cumulative ranking probability curve (SUCRA) of the comparisons 
A

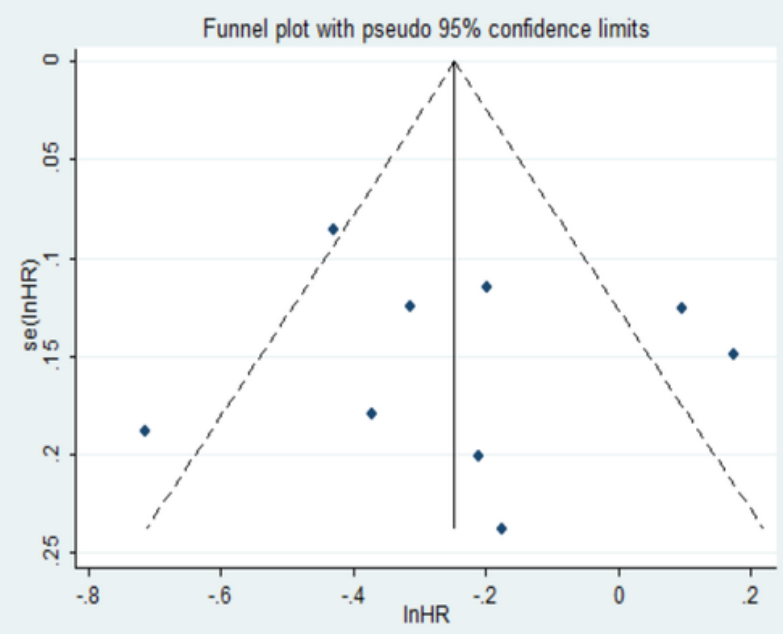

B

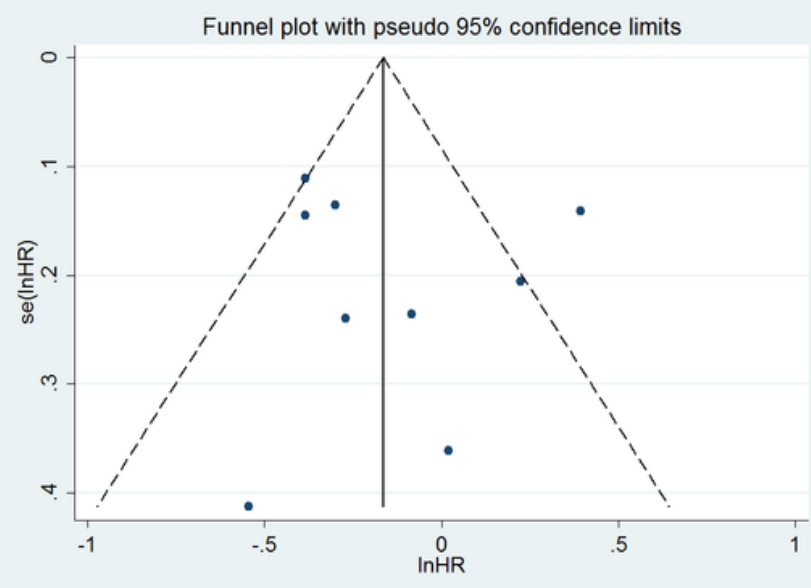

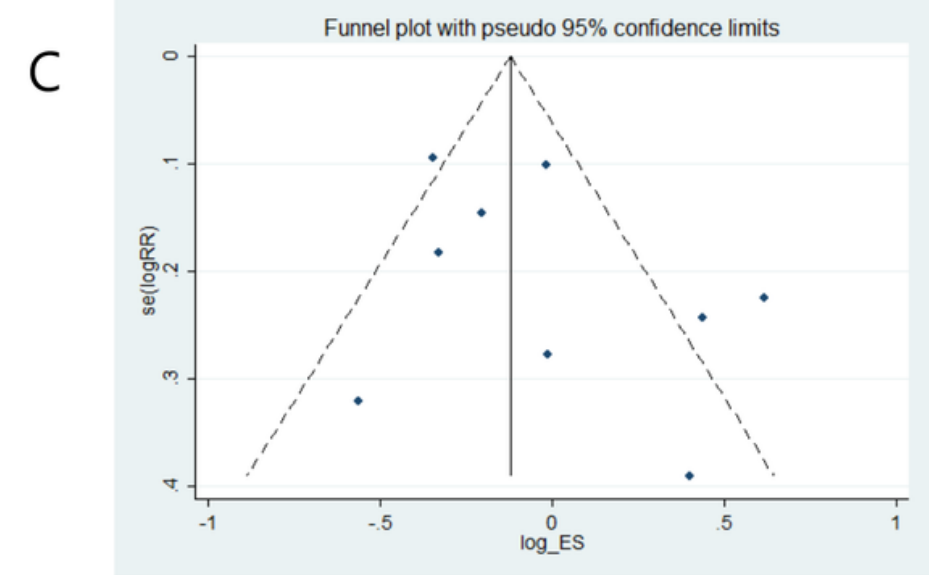

Figure 6

Funnel plot for publication bias. (A) PFS, (B) OS, and (C): ORR 